\title{
A EDUCAÇÃO AMBIENTAL NA EDUCAÇÃO INFANTIL: LIMITES E POSSIBILIDADES
}

\author{
THE ENVIRONMENTAL EDUCATION IN CHILDHOOD EDUCATION: limits and \\ possibilities
}

LA EDUCACIÓN AMBIENTAL EN LA EDUCACIÓN INFANTIL: límites y posibilidades

\author{
Daniele Saheb \\ Professora Doutora da Pontifícia Universidade Católica do Paraná (PUCPR). \\ danisaheb@yahoo.com.br \\ Daniela Gureski Rodrigues \\ Especialista em Educação Ambiental. \\ dany_gureski@yahoo.com.br
}

\begin{abstract}
RESUMO: Este artigo objetiva problematizar as características do pensamento e da ação dos docentes da Educação Infantil sobre a temática ambiental nas esferas pública e privada. Trata-se de uma pesquisa com análise qualitativa, cujos instrumentos utilizados foram entrevistas, análise da proposta pedagógica e observação do ambiente educativo. O estudo, realizado em Curitiba, Paraná, revelou a partir da análise das propostas pedagógicas das duas instituições que existe a orientação para o trabalho interdisciplinar com a Educação Ambiental na Educação Infantil. Constatou-se por meio dos discursos que todos os docentes pesquisados concordam com a importância da inserção da Educação Ambiental na Educação Infantil e alegam trabalhar com o tema em suas turmas. As observações do ambiente demonstraram atividades voltadas principalmente à reutilização de materiais recicláveis para a confecção de brinquedos, observação da natureza e horta. Apesar dos avanços do debate sobre a Educação Ambiental na Educação Infantil impulsionado pelas Diretrizes Curriculares Nacionais de Educação Ambiental (2012) e das Diretrizes Curriculares Nacionais para a Educação Infantil (2009), ainda mostrou-se predominante nos discursos e na prática pedagógica uma concepção de cunho reducionista e naturalista.
\end{abstract}

PALAVRAS-CHAVE: Educação ambiental. Educação infantil. Prática pedagógica.

ABSTRACT: This article aims to discuss the action and thoughts characteristics from the early childhood education teachers on the environmental issues in the public and private spheres. This is a qualitative analysis survey, which the instruments used were interviews, pedagogical proposal analysis and educational environment observation. The study, conducted in Curitiba, Paraná, showed from the pedagogical proposal analysis of the two institutions that there is guidance for the interdisciplinary work with the environmental education in early childhood education. It was found, through the speeches, that all surveyed teachers agree with the importance of the environmental education in early childhood education and claim to work with this subject in their classes. The environmental observations demonstrated activities related mainly to recyclable material re-use to manufacture toys, nature observation and garden. Despite advances on the environmental education debate in early childhood education driven by the Environmental Education National Curriculum Guidelines (2012) and the Early Childhood Education National Curriculum Guidelines (2009), it is still proved to be predominantly in speeches and in the pedagogical practice a reductionist and naturalist concept.

KEYWORDS: Environmental Education. Childhood Education. Pedagogical practice.

Artigo recebido em janeiro de 2016

Aprovado em março de 2016 
RESUMEN: Este estudio tiene como objetivo plantearse como problema las características del pensamiento y de las acciones del profesorado de la Educación Infantil sobre tema medioambiental en las esferas públicas y privada. Se trata de una investigación con análisis cualitativa, a los cuales los instrumento utilizados fueron entrevistas, análisis de la propuesta pedagógica y observación del entorno educativo. La investigación, realizada en Curitiba, Paraná, puso de manifiesto a partir del análisis de las propuestas pedagógicas de dos instituciones, donde hay orientación para el trabajo interdisciplinario entre la Educación Ambiental y la Educación Ambiental en la Educación Infantil. Se comprobó a través de los discursos que todo el profesorado investigado concuerda con la importancia de la inclusión de la Educación Ambiental a la Educación Infantil donde alega trabajar con el tema en sus clases. Las observaciones del medio ambiente demuestran actividades enfocadas sobre todo a la reutilización de materiales reciclables para la elaboración de juguetes, observación de la naturaleza y huerta. Pese a los avances del debate sobre Educación Medio ambiental en la Educación Infantil impulsado por las Directrices Curriculares Nacionales de Educación Ambiental (2012) y de las Directrices Curriculares Nacionales para la Educación Infantil (2009), demostró todavía dominante en los discursos y en la práctica pedagógica una concepción de molde reduccionista y naturalista.

PALABRAS CLAVE: Educación Ambiental. Educación Infantil. Práctica Pedagógica. 
A EDUCAÇÃO AMBIENTAL | Daniele Saheb e Daniela Gureski Rodrigues

\section{1| INTRODUÇÃO}

Esta pesquisa teve como intuito problematizar as práticas pedagógicas de Educação Ambiental (EA) no contexto da Educação Infantil (El). Em especial, teve-se como objetivo identificar as práticas de EA realizadas pelos docentes de Educação Infantil de um Centro Municipal de El (CMEl) e de um Centro de El da rede privada, ambos no município de Curitiba, Paraná. Para tanto, esta pesquisa de abordagem qualitativa, utilizou-se dos seguintes instrumentos para a análise dos dados: a análise documental - Proposta Pedagógica, a observação de atividades e entrevistas com educadores das duas instituições.

A importância deste estudo diz respeito principalmente a dois aspectos. O primeiro se refere à inserção da Educação Ambiental (EA) no currículo da escola brasileira, que foi reafirmada por meio das Diretrizes Curriculares Nacionais para a EA (DCNEA) de 15 de junho de 2012. E o segundo decorre da necessidade da ampliação do debate acerca da qualidade das práticas e currículo na Educação Infantil (EI), uma vez que a alteração na Lei de Diretrizes e Bases da Educação no Brasil (LDB) prevê em seu artigo $4^{\circ}$ a abrangência do ensino obrigatório para a faixa etária de 4 a 17 anos.

Outro aspecto que não pode escapar à reflexão desenvolvida neste artigo diz respeito à formação dos educadores tanto para a EA quanto para a El, devido a uma importante conquista: as Diretrizes Curriculares Nacionais para o curso de graduação em Pedagogia, licenciatura. $O$ referido documento aborda a temática socioambiental, sob o enfoque do conhecimento ambientalecológico, o qual deve permear a formação do pedagogo.

Este aspecto é importante, visto que orienta o desenvolvimento de discussões acerca da temática socioambiental no currículo do curso. Lembrando que o egresso do curso de Pedagogia, que tem como foco a docência e a gestão na Educação Básica, tem a responsabilidade de promover ações pedagógicas voltadas à promoção da EA na Educação Infantil e nos Anos Iniciais. Esta demanda justifica a necessidade de que o profissional pedagogo receba em sua formação inicial conhecimentos sobre a EA.

A esse respeito ressalta-se que a trajetória da El no Brasil apresenta documentos importantes que preveem o trabalho pedagógico com a EA nesta etapa da Educação Básica, entre eles destacam-se o Referencial Curricular Nacional para a El (BRASIL, 1998) e as Diretrizes Curriculares Nacionais para a El (BRASIL, 2009; 2010).

Este estudo, portanto, coloca-se diante deste contexto no qual a temática ambiental e a qualidade na El se constituem como objetos de interesse e necessidade social. Deste modo, a implementação da EA no cotidiano e nas instituições de ensino, apontam para um caminho diante da crise socioambiental. Assim, acredita-se que este estudo possa contribuir para ampliar as reflexões acerca do processo de inserção da EA no contexto escolar, bem como para a qualidade da Educação Infantil, constituindo-se, portanto, como um elemento importante no caminho para a transformação rumo a uma sociedade mais solidária, justa e humanitária.

\section{2 | REVISITANDO A EDUCAÇÃO AMBIENTAL}

A trajetória histórica da EA mostra que aos poucos essa dimensão da educação vem conquistando seu espaço e se inserindo nos debates pedagógicos nas instituições de ensino no Brasil. Entre seus importantes marcos elegeram-se alguns como a Conferência Intergovernamental sobre Educação Ambiental realizada em Tbilisi, capital da Geórgia (ex-URSS) em 1977, a qual se constitui como o ponto culminante do Programa Internacional de Educação Ambiental. Nessa 
A EDUCAÇÃO AMBIENTAL | Daniele Saheb e Daniela Gureski Rodrigues

conferência foram definidos os objetivos e as estratégias pertinentes em nível nacional e internacional.

No Brasil a Conferência Rio-92 estabelece uma proposta de ação para os próximos anos, denominada Agenda 21. E, por meio deste Tratado de Educação Ambiental para Sociedades Sustentáveis e Responsabilidade Global, assinado durante a RIO 92, enfatiza, na diretriz 19 do Plano de Ação, a importância de mobilizar as instituições de educação superior para o ensino, pesquisa e extensão em Educação Ambiental e a criação, em cada universidade, de centros interdisciplinares para o meio ambiente. O Capítulo 36 da Agenda 21 destaca o papel relevante da Universidade para o estímulo da pesquisa e de uma educação comprometida com a sustentabilidade.

Além da Conferência Rio-92, que foi de grande importância, destacam-se no histórico da EA no Brasil consideráveis aspectos como a Política Nacional de Meio Ambiente, que apresentava em seu segundo artigo, a educação ambiental a todos os níveis de ensino (BRASIL, 1981).

Ressaltam-se ainda que alguns documentos que orientam a Educação Básica, propostos pelo Ministério da Educação (MEC), reafirmam a importância de se trabalhar com a EA em todos os níveis de ensino. Entre eles podemos citar as Diretrizes Curriculares Nacionais para a Educação Infantil - DCNEI (BRASIL, 2009), que trata a EA como princípio de respeito ético ao meio ambiente. Cabe mencionar também os Parâmetros Curriculares Nacionais (BRASIL, 1997), que situam o Meio Ambiente (MA) como tema transversal, e que, portanto, devem ser integrados a todas as disciplinas do currículo escolar. Além dos documentos citados, o Referencial Curricular Nacional para a Educação Infantil (BRASIL, 1998) apresentam como objetivo geral o observar e o explorar o meio ambiente em um eixo nomeado "natureza e sociedade" no qual a criança, por meio da sua curiosidade, cada vez mais desenvolve a sua capacidade de agir, explorando e observando tudo que encontra ao seu redor, procurando soluções para melhorar a sua própria qualidade de vida. Dessa maneira a El constitui-se como um momento importante para o desenvolvimento de uma personalidade moral voltada para o meio ambiente.

O evento mais recente relacionado com a EA foi a Conferência das Nações Unidas sobre o Desenvolvimento Sustentável, conhecida como RIO+20, realizada entre os dias 13 a 22 de junho do ano de 2012, na cidade do Rio de Janeiro, definindo a agenda do desenvolvimento sustentável para as próximas décadas. O principal objetivo desta conferência foi a renovação do compromisso político com o desenvolvimento sustentável. Em maio de 2012 foram criadas as Diretrizes Curriculares Nacionais para a Educação Ambiental para facilitar a discussão da implementação da mesma em todos os níveis de ensino, sendo um documento para orientar os sistemas de ensino e as instituições, desde a Educação Básica até o Ensino Superior (ES), tratando a EA como uma prática educativa integrada, contínua e permanente.

A trajetória da EA demonstra a gradativa ampliação do debate no meio educacional, principalmente no que diz respeito à Educação Básica. Contudo, ainda hoje encontram-se práticas nas quais a EA é reduzida a atividades voltadas à separação do lixo e à economia de água, desprovida da reflexão e questionamento sobre o processo como um todo. Esta constatação revela a urgência do desenvolvimento de estudos e pesquisas que aprofundem a relação entre a EA e a Educação Básica.

Nesse sentido, cabe à escola uma parcela de contribuição nessas novas buscas. Deve-se trabalhar na perspectiva da superação da visão ingênua e reducionista das novas gerações, assumindo a EA como um instrumento que pode e deve ser utilizado como estratégia para o embasamento de discussões acerca de problemas concretos. Com base nas afirmações anteriores, compreende-se que para que seja vivenciada a dimensão escolar da EA torna-se fundamental romper com os comportamentos pré-estabelecidos e estereotipados, o que deve necessariamente acontecer no processo de formação inicial e continuada de professores, como um caminho 
A EDUCAÇÃO AMBIENTAL | Daniele Saheb e Daniela Gureski Rodrigues

necessário para que a dimensão ambiental amplie e solidifique seu espaço nas discussões e práticas na Educação Infantil.

\section{3 | A EDUCAÇÃO AMBIENTAL NA EDUCAÇÃO INFANTIL}

O reconhecimento do direito à educação pelas crianças e a instituição da El como a primeira etapa da Educação Básica pela Lei de Diretrizes e Bases da Educação Nacional (Lei n 9.394/96) intensificaram o debate em torno das políticas públicas e práticas voltadas às crianças de zero a seis anos no Brasil. A recente alteração na LDB (Lei n 12.796 , de 4 de abril de 2013) que determina a última etapa da El como obrigatória pode ser compreendida como expressão das reflexões desenvolvidas nos últimos vinte anos acerca desta etapa da Educação Básica. Nesse contexto, cabem alguns questionamentos como, por exemplo, os que dizem respeito ao papel que a El tem desempenhado junto às crianças; Aos valores e padrões trabalhados; A contribuição das práticas desenvolvidas no cotidiano da El para que as crianças construam relações pautadas na solidariedade e no respeito com as pessoas e com o meio ambiente.

Esses desafios são congruentes com as preocupações propostas explicitadas em importantes documentos e estudos de EA. Entre eles destaca-se a Carta da Terra e a Agenda 21, os quais contribuíram para que a questão ambiental conquistasse maior espaço e importância no âmbito pedagógico da Educação Básica, especialmente na El.

A Agenda 21, elaborada a partir da Conferência Rio-92, estabelece uma proposta de ação voltada para a sustentabilidade para os próximos anos, destacando como necessária a construção de uma educação ambiental escolar.

A Carta da Terra é uma declaração de princípios éticos fundamentais para a construção de uma sociedade global justa, sustentável e pacífica, aprovada pela UNESCO em março de 2000. Ela buscou inspirar para a compreensão da interdependência global e responsabilidade compartilhada, voltada ao bem-estar de toda a família humana, da grande comunidade da vida e das futuras gerações.

Outros documentos aprovados pelo Ministério da Educação (MEC) - já mencionados neste trabalho - oferecem aos docentes subsídios para a reflexão quanto à prática pedagógica da EA na Educação Infantil, entre eles merecem especial atenção os Referencias Curriculares Nacionais para a Educação Infantil (BRASIL, 1998), e as Diretrizes Curriculares Nacionais para a Educação Infantil - DCNEI (BRASIL, 2009). Os RCNEI incluem entre os objetivos gerais a necessidade da criança "observar e explorar o ambiente com atitude de curiosidade, percebendo-se cada vez mais como integrante, dependente e agente transformador do meio ambiente e valorizando atitudes que contribuam para a sua conservação" (BRASIL, 1998, p. 63). Entretanto, em nenhum momento, em seus três volumes, os RCNEI mencionam o termo Educação Ambiental, apesar de demonstrarem alguns aspectos convergentes em um eixo intitulado Natureza e Sociedade que engloba a questão ambiental reunindo questões ao mundo social e natural, definindo como conteúdos deste bloco: a valorização de atitudes de manutenção e preservação dos espaços coletivos e do meio ambiente (BRASIL, 1998, p. 184).

Por meio dos conteúdos e objetivos propostos observa-se um enfoque preservacionista ou naturalista, cuja característica principal é a ênfase na proteção ao mundo natural. Segundo Carvalho (2005, p. 33), essa prática pode ficar "limitada ao campo da aprendizagem, no sentido comportamental do termo, o que a restringe ao campo do condicionamento, do adestramento, do treinamento". 


\title{
A EDUCAÇÃO AMBIENTAL | Daniele Saheb e Daniela Gureski Rodrigues
}

As DCNEI (BRASIL, 2009) também não apresentam a denominação EA, porém demonstram o enfoque socioambiental em alguns de seus artigos, entre eles destacam-se os princípios de respeito ético, político e estético ao meio ambiente, enfatizados no artigo $6^{\circ}$.

Os princípios definidos pelas DCNEI (BRASIL, 1999; 2010) devem perpassar a proposta pedagógica das instituições de El no Brasil, e evidenciam a relação entre a temática socioambiental e educação para a cidadania. Este aspecto implica na emergência de novos saberes no currículo escolar. Nesse contexto a EA ganha especial relevo e impõe aos educadores a necessidade de repensar os saberes e a prática pedagógica apoiados na visão reducionista do conhecimento em prol de propostas alicerçadas em saberes que instrumentalizem os indivíduos a assumir uma postura baseada na ética, na cidadania e na solidariedade.

\begin{abstract}
Art. $7^{\circ} \mathrm{Na}$ observância destas Diretrizes, a proposta pedagógica das instituições de Educação Infantil deve garantir que elas cumpram plenamente sua função sociopolítica e pedagógica: $\mathrm{V}$ - construindo novas formas de sociabilidade e de subjetividade comprometidas com a ludicidade, a democracia, a sustentabilidade do planeta e com o rompimento de relações de dominação etária, socioeconômica, étnico-racial, de gênero, regional, linguística e religiosa. (BRASIL, 2010, p. 14)
\end{abstract}

O respeito à diversidade e à cultura local, que se constitui como uma das bases da $E A$, é ressaltado também no artigo $8^{\circ}$ das DCNEl (2009), o qual destaca a diversidade das infâncias brasileiras orientando a organização de propostas pedagógicas que estejam articuladas com a comunidade e a cultura das crianças. Esse aspecto é ainda mais importante na medida em que amplia o diálogo entre a El e a Educação do Campo, no âmbito de uma legislação com abrangência nacional.

\footnotetext{
$\S 3^{\circ}$ - As propostas pedagógicas da Educação Infantil das crianças filhas de agricultores familiares, extrativistas, pescadores artesanais, ribeirinhos, assentados e acampados da reforma agrária, quilombolas, caiçaras, povos da floresta, devem: IV - valorizar e evidenciar os saberes e o papel dessas populações na produção de conhecimentos sobre o mundo e sobre o ambiente natural. (BRASIL, 2009, p. 3).
}

O parágrafo mencionado corrobora com uma das preocupações da $E A$, ou seja, que os indivíduos sejam estimulados a preservar e a valorizar o multiculturalismo, para que as populações historicamente excluídas tenham condições de refletir sua realidade, construir conhecimentos acerca de suas problemáticas centrais e então terem acesso à melhoria na qualidade de vida. Essa perspectiva pode ser observada nas DCNEA:

\footnotetext{
V - articulação na abordagem de uma perspectiva crítica e transformadora dos desafios ambientais a serem enfrentados pelas atuais e futuras gerações, nas dimensões locais, regionais, nacionais e globais; VI - respeito à pluralidade e à diversidade, seja individual, seja coletiva, étnica, racial, social e cultural, disseminando os direitos de existência e permanência e o valor da multiculturalidade e plurietnicidade do país e do desenvolvimento da cidadania planetária (BRASIL, 2012, p. 4).
}

Ressalta-se aqui a dimensão socioambiental da EA, a qual supera a concepção naturalista de meio ambiente e valoriza a interação entre a sociedade e a natureza como importante para a sustentabilidade do planeta. Desta forma, a proposta pedagógica da Educação Infantil deve ter como foco o desenvolvimento de metodologias que incentivem a construção de valores socioambientais voltados à realidade das crianças e de sua comunidade, a partir de saberes locais e tradicionais aliados aos científicos. 
A EDUCAÇÃO AMBIENTAL | Daniele Saheb e Daniela Gureski Rodrigues

O artigo $9^{\circ}$ das DCNEI (2009, p. 3) afirmam que o currículo da El deve ter como eixo práticas pedagógicas que:

\begin{abstract}
$X$ - promovam a interação, o cuidado, a preservação e o conhecimento da biodiversidade e da sustentabilidade da vida na Terra, assim como o não desperdício dos recursos naturais; [...] VIII - incentivem a curiosidade, a exploração, o encantamento, o questionamento, a indagação e o conhecimento das crianças em relação ao mundo físico e social, ao tempo e à natureza; VIII - incentivem a curiosidade, a exploração, o encantamento, o questionamento, a indagação e o conhecimento das crianças em relação ao mundo físico e social, ao tempo e à natureza.
\end{abstract}

Observa-se no inciso X do artigo $9^{\circ}$, portanto, a preocupação com o desenvolvimento de práticas pedagógicas na El que estimulem o contato da criança com temas relacionados ao meio ambiente por meio da vivência. Face a essa orientação, destaca-se que as crianças nascem e vivem em um contexto integrante à natureza, desde muito cedo deparam-se com situações decorrentes da intervenção inadequada do homem com o meio ambiente, como por exemplo a instabilidade climática e a poluição industrial. Cabe, portanto, ao professor de El a organização de metodologias que tenham como objetivo o desenvolvimento de vínculo afetivo entre a criança e a natureza, superando propostas tradicionais baseadas na aquisição de informações descontextualizadas a respeito da questão ambiental. A perspectiva atual deve considerar as inter-relações, o diálogo, desenvolvendo nos sujeitos o sentimento de responsabilidade e solidariedade.

$\mathrm{O}$ artigo ressalta ainda a importância do estimulo à curiosidade da criança. Nesse sentido destaca-se que as questões ambientais devem primeiramente ser significativas para as crianças, e em se tratando de Educação Infantil, devem partir da observação do ambiente no qual estão inseridos, que conhecem e que portanto possuem uma relação afetiva.

Nota-se em relação aos dois documentos apresentados: RCNEI (1998) e DCNEI (2009), que ambos não mencionam o termo Educação Ambiental, porém abordam a dimensão ambiental de forma implícita, os RCNEI de maneira mais limitada e a DCNEI demonstrando avanços importantes. Diante desse contexto cabe destacar que a aprovação das DCNEA (2012) marca uma importante contribuição para a implementação da EA em todos os níveis de ensino como uma prática educativa integrada, contínua e permanente. No tocante à $\mathrm{El}$ o momento foi ainda mais oportuno devido à alteração na Lei de Diretrizes e Bases da Educação no Brasil (LDB) tornando obrigatório o ensino a partir dos quatro anos. Este fato indica a importância da ampliação do debate acerca da qualidade das práticas e currículo na Educação Infantil (EI).

Outro aspecto a ser ressaltado é a constatação de que cada vez mais as famílias têm a necessidade matricular seus filhos em Centros de Educação Infantil, cujos docentes acabam compartilhando com a família a educação das crianças. Este fato aumenta a responsabilidade quanto à necessidade de uma formação para professores de Educação Infantil que possam atuar em diferentes contextos e em diferentes dimensões do processo educativo, incluindo a dimensão ambiental.

Para isso é necessário mais do que informações e conceitos: esses profissionais precisam trabalhar com atitudes, com a formação em valores pautados na ética, na cooperação e no respeito, ou seja, a ideia de ambiente relacionada à dimensão cultural e social. Portanto a EA deve ser desenvolvida por meio da interdisciplinaridade, a qual é nutrida pela Complexidade. Assim sendo, a El deve introduzir a temática ambiental de forma interdisciplinar, para que as crianças sejam estimuladas a construir conhecimentos acerca dos temas socioambientais com intuito de se superar o senso comum, a desenvolver capacidades de se sensibilizar, compreender e repensar a problemática socioambiental e finalmente desenvolver valores socioambientais como alicerce para a as ações dos sujeitos no seu cotidiano e na vida em sociedade. Ou seja, a criança necessi- 


\section{A EDUCAÇÃO AMBIENTAL | Daniele Saheb e Daniela Gureski Rodrigues}

ta aprender diversos conhecimentos e também a habilidade em identificar os desafios e criar alternativas. Portanto a EA na El demanda uma metodologia que favoreça a resolução de problemas, mas também a criatividade e a imaginação, valorizando a contextualização e o diálogo dos saberes. Por isso, além da valorização do interesse e do significado no trabalho com problemas reais, devem-se considerar propostas nas quais a criança aja, pesquise, pergunte, realize, enfim, seja protagonista.

Diante da reflexão anterior toma especial relevo o papel do professor frente a EA. Cabe a este profissional a busca pelos conceitos e informações sobre questões socioambientais. Os docentes necessitam entrar em contato direto com os diferentes grupos sociais, observar relações que interpõem-se ao meio ambiente e explorá-lo, junto com as crianças, coletar informações sobre as relações entre o meio ambiente e a sociedade, buscando coordenar situações de ensino, onde provoquem os alunos a buscar e se apropriar do conhecimento, levando o mesmo para ser aplicado não somente na escola, mas para a vida.

Denota-se, assim, a importância do trabalho do docente em introduzir a questão ambiental em sua prática pedagógica na $\mathrm{El}$, sendo o mesmo um referencial para as crianças de como descobrir respostas e encontrar soluções para esta temática. A relação entre a criança e o meio ambiente se dá através de sua própria manipulação dos objetos. Através da sua curiosidade e necessidade em explorar o meio, se integrando a ele.

\footnotetext{
[...] pois não apenas as salas de aula, mas todos os lugares são propícios às aprendizagens: terreiros, jardins, plantações, criações, riachos, praias, dunas, descampados; tudo que está entorno do bairro, a cidade, seus acidentes geográficos, pontos históricos e pitorescos, as montanhas, o mar [...]. Além de se constituírem com espaços de brincar livremente e relaxar, estes locais podem também ser explorados como lugar de ouvir histórias, desenhar e pintar, espaços de aprendizagem, em que se trabalha uma diversidade de conhecimento. (BRASIL, 2010, p. 9).
}

Portanto, acredita-se que por meio da construção de conhecimentos ambientais, para uma perspectiva da cidadania, as instituições de El e seus profissionais estarão cumprindo seu papel diante da sociedade, criando propostas pedagógicas que compreendam o desenvolvimento social e sustentável, voltados para a temática ambiental.

\section{4 | METODOLOGIA E RESULTADOS}

A referência metodológica foi a pesquisa qualitativa com o enfoque bibliográfico, documental e exploratório em dois Centros de Educação Infantil, sendo um Municipal e outro da rede privada, ambos em Curitiba, Paraná. Com o objetivo de conhecer a concepção e práticas pedagógicas de EA dos educadores de Educação Infantil foram utilizados como instrumento de coleta de dados a observação de aulas, a análise documental (Projeto Político Pedagógico das instituições) e entrevistas com os educadores.

Foram foco de análise as cinco turmas da instituição pública sendo elas: Berçário (corresponde a faixa etária de 3 meses a 1 ano), Maternal I (1 a 2 anos), Maternal II ( 2 a 3 anos), Maternal III ( 3 a 4 anos), Pré (4 a 5 anos) e as profissionais atuantes em cada uma delas. E da instituição privada: berçário, maternal I, maternal II, pré I e pré II, correspondendo às mesmas faixas etárias. Para posterior estruturação da coleta de dados foi observada a utilização dos espaços físicos internos e externos como disparadores de atividades pedagógicas com enfoques em EA ou com abordagem superficial relativa ao tema, como exploração livre partindo do interesse individual das crianças. 


\section{A EDUCAÇÃO AMBIENTAL | Daniele Saheb e Daniela Gureski Rodrigues}

Concomitantemente foram analisados os documentos que regem a proposta curricular para a Educação Infantil na Rede Municipal de Curitiba e o Projeto Político Pedagógico do CMEI bem como o Projeto Político Pedagógico da instituição privada. As diretrizes curriculares municipais de Curitiba estão subdivididas por área de formação e faixa etárias para o desenvolvimento de objetivos de 0 a 3 anos e 4 e 5 anos. Os objetivos que demonstram relação com a temática ambiental estão inseridos na área de Relações Naturais voltados principalmente à perspectiva de observar, diferenciar objetos, animais e paisagens, ou seja, percebeu-se a predominância de um enfoque naturalista, de um sujeito como observador externo e não como parte integrante da natureza. $\mathrm{O}$ Projeto Político Pedagógico vigente do CMEl foi elaborado no ano $2004{ }^{1}$. Nele foi possível verificar na concepção de criança uma alusão à questão ambiental:

Demonstra um interesse muito grande, um fascínio sobre os conhecimentos da natureza, dos grupos sociais. E assim ao longo do seu processo de desenvolvimento vai construindo valores e atitudes para compreender, se relacionar, interagir com a natureza e a sociedade. (CURITIBA, 2004, p. 13).

A citação denota um enfoque de separação entre natureza e sociedade, reforçando a ideia do ser humano como observador externo que precisa ser ensinado a interagir com a natureza. Mostra ainda uma ênfase preservacionista:

É importante que comece a interagir com a conservação e preservação do meio ambiente, através de ações cotidianas como: estabelecimento de locais adequados para a separação do lixo. Consumo reduzido de água, energia elétrica. (CURITIBA, 2004, p. 13).

O documento enfatiza a ideia de que a criança precisa aprender a cuidar do meio ambiente e a preservá-lo, porém não foi encontrada nenhuma alusão à perspectiva de interdependência entre ser humano e meio ambiente. Foi possível constatar também que o documento alega a necessidade de inserção da prática de separação do lixo, sem, porém, relações com a discussão sobre o consumo consciente. Uma contradição percebida por meio da observação foi a de que, mesmo constando no PPP a ênfase no ensino quanto à separação do lixo no CMEI, nas salas de aula há apenas uma lixeira, impossibilitando profissionais e crianças de realizarem essa separação. Há também um gasto excessivo com manutenção de torneiras externas, pois sempre apresentam vazamentos devido a atos de vandalismo da comunidade.

No PPP da instituição privada foram encontrados temas referentes aos fenômenos naturais como, por exemplo, a preservação da água na área do conhecimento Natureza e Sociedade, porém são temas que não demonstram no documento nenhuma reflexão ou menção à EA.

Ao todo, foram realizadas entrevistas com dezoito educadores. A entrevista foi semiestruturada e as questões propostas buscaram destacar os seguintes temas: a concepção dos educadores sobre EA, suas fontes de acesso ao conhecimento sobre a EA e as práticas que desenvolvem sobre a EA junto às crianças da Educação Infantil.

Quanto às concepções dos educadores sobre EA, ambos, da rede pública e privada, demonstraram o predomínio da ideia de preservação e cuidados com a natureza. Como por exemplo:

"Educar para viver melhor em um lugar com qualidade de vida". (Docente A).

"Uma educação relacionada com o meio ambiente, como cuidar dele e das pessoas que nele vivem". (Docente B).

\footnotetext{
${ }^{1}$ Segundo a pedagoga, o PPP desta instituição estava sendo reformulado durante o período da pesquisa, visto que segundo a legislação no Brasil, este documento precisa ser atualizado no máximo, no período de cinco anos.
} 
"Uma educação que vise a conscientização das pessoas para os problemas ambientais que existem, como podem ser resolvidos e métodos preventivos". (Docente C).

Constatamos que as docentes têm certa dificuldade em compreender a EA como uma educação que prepara para a cidadania, prevendo a formação do sujeito, abrangendo o ambiente social e natural, conforme define as DCNEA:

A Educação Ambiental visa à construção e ao desenvolvimento de conhecimentos, habilidades, atitudes e valores sociais, voltados para a conservação do meio ambiente natural e construído, essencial para a qualidade de vida e sua sustentabilidade. (BRASIL, 2012, p. 2).

As DCNEA enfatizam a perspectiva problematizadora das ações sociais, entretanto os educadores mostraram ter como predominante uma concepção voltada à preservação da natureza, desvinculada da ação humana. Esse aspecto demonstra a necessidade de maior aproximação entre os referenciais teóricos e documentais e as atitudes cotidianas das instituições de Educação Infantil. Cabe ainda a reflexão acerca da formação de professores e a gradativa necessidade da compreensão do papel do docente diante do grave cenário de crise local e global. Essa demanda precisa ser foco dos processos de formação inicial e continuada dos profissionais da educação, para que atendam adequadamente aos objetivos e princípios propostos pela EA.

A outra parcela dos dados coletados apresenta como aspecto marcante a importância dos cuidados com a natureza. Essas práticas mostram-se frequentes nas duas instituições pesquisadas, o que se justifica no trabalho com crianças de zero a três anos, que estão vivenciando suas primeiras experiências na sua relação com o ambiente, ainda marcado por sensações e descobertas. Segundo Tiriba (2010, p. 2),

creches e pré-escolas são espaços privilegiados para aprender-ensinar porque aqui as crianças colhem suas primeiras sensações, suas primeiras impressões do viver. Neste sentido, a dimensão ambiental não poderia estar ausente, ou a serviço da dimensão cultural, ambas deveriam estar absolutamente acopladas.

Os docentes relataram ainda que muitas crianças tem o acesso limitado a sua casa, permanecendo a maior parte do seu tempo brincando no quarto e com aparelhos eletrônicos. À menção feita pelos educadores sobre o cuidado como um aspecto de EA a ser trabalhado na El pode ser relacionado com a ideia de cuidado de Boff (2012), que ressalta a importância de se prender a cuidar da mãe terra e de desenvolver com o meio ambiente um vínculo afetivo, justificando-se então como parte integrante do processo formativo do sujeito ambientalmente inserido. Portanto ao desenvolverem a atenção sobre os espaços e elementos que compõem a natureza, as crianças constroem vínculo afetivo com o meio ambiente, aspecto essencial para a continuidade do trabalho pedagógico com a EA. Esses aspectos são reforçados na fala dos educadores:

"Acredito que elas precisam aprender desde pequenos a respeitar (logo) cuidar e zelar por algo que é muito importante para todos".

"Quando aprendem a cuidar desde pequenos, se tornam cidadãos conscientes. Percebe-se claramente e importância do trabalho ainda na primeira infância".

Para Carvalho (2004) a ação é elemento fundamental no processo de ensino e aprendizagem em EA, "atitudes são predisposições para que um indivíduo se comporte de tal ou qual maneira, e assim podem ser preditivas de comportamento". Desta forma corrobora a ideia de que é importante incentivar as crianças a terem cuidado com os diversos elementos da natureza e também a preservar os recursos naturais e necessários para qualidade de vida no planeta. 


\section{A EDUCAÇÃO AMBIENTAL | Daniele Saheb e Daniela Gureski Rodrigues}

Após criteriosa análise das concepções dos educadores sobre EA, identificou-se a necessidade da superação do senso comum quanto ao tema, elemento preocupante visto que o profissional atrela sua prática à teoria adquirida em suas vivências acadêmicas ou cotidianas. Para Guarnieri (2003, p. 12), "a prática mediatiza a relação do professor com a teoria, o que implica um movimento de superação de adesão acrítica às teorias e aos modismos pedagógicos". Quando indagados sobre as fontes de suas informações utilizadas como base para o planejamento das atividades de EA, os professores da rede pública e da privada se restringem aos cadernos pedagógicos do município, práticas dos colegas e materiais encontrados na internet.

Ressalta-se, conforme já exposto neste artigo, que o ponto nodal para o entendimento de EA diz respeito à problematização das práticas sociais, a partir da crise que assola a relação dos seres humanos com o ambiente. Trata-se portanto de uma EA crítica, que reflita, que discuta em busca de alternativas para o enfrentamento dessa crise. Na EA escolar esse papel cabe ao educador e por isso esta pesquisa buscou identificar a compreensão de meio ambiente e EA dos educadores, bem como o significado que atribuem às suas práticas pedagógicas em $E A$. Em estudos anteriores foi possível compreender que a ideia de Meio Ambiente tende a não ser a mesma na mente de diferentes pessoas. Provavelmente ela dependerá da formação profissional, das vivências, do lugar em que se vive. Entre os professores entrevistados houve o predomínio de elementos naturais ou ainda somente temas pontuais que relacionam a EA com reciclagem e preservação da água, como é possível constatar nas seguintes falas:

"EA é ensinar a criança a cuidar da natureza."

"É aprender a agir de forma correta com a natureza, como reciclar o lixo e preservar a água".

"Ensinar a respeitar as plantas, animais e recursos naturais".

"A EA é o ensino de conhecimentos sobre a natureza, trabalhamos em relações naturais. As crianças aprendem a não desperdiçar água, a separar o lixo, essas coisas".

Em relação às práticas pedagógicas foram recorrentes os temas: lixo, horta e água. Dos 18 educadores, 11 explicaram desenvolver práticas e atividades voltadas à separação e reciclagem do lixo e utilização de sucata na confecção de brinquedos, sem porém mencionar aspectos que envolvam o consumo consciente. Constatou-se que a EA na EI nos espaços pesquisados acontece por meio de conteúdos relativos a Relações Naturais e Conservação da Natureza, ficando ausentes o diálogo com os aspectos das relações sociais, a contextualização e problematização de situações da realidade.

As duas instituições realizam atividades com a horta e segundo os educadores de ambas, o objetivo é a aprendizagem do hábito de cuidar da terra a partir do plantio de flores, pequenas árvores, legumes e verduras. Pelo menos uma vez ao ano as crianças vivenciam experiências como esta. A prática pedagógica a partir da horta é corroborada pelas Diretrizes Curriculares Municipais de Curitiba para a Educação Infantil,

O contato com a natureza é de fundamental importância para as crianças, e compreender as relações sociais que se estabelecem nesse contexto favorece a elas a construção de noções de reciprocidade sobre suas ações e consequências no meio. (CURITIBA, 2012, p. 32).

Entretanto, observou-se que as práticas ficam restritas à atividade específica do plantio das mudas e sementes, acompanhamento da evolução e cuidado das mesmas e depois alimentação. Não foi possível identificar práticas que discutissem com as crianças a importância da alimentação saudável a partir de sua realidade, com investigações com as famílias, consumo consciente e saúde, a devida contextualização e conexão com os objetivos e métodos. 
Outro aspecto observado foi a dificuldade de se compreensão do ambiente em suas intra e inter-relações, o que denota um pensamento reducionista de que a escola é uma parte isolada da comunidade. No Centro Municipal de El a horta se encontra em estado de inutilidade, foi investido muito em terra e construção de muretas, mas durante o fim de semana que não há expediente com crianças a comunidade invadiu e fez uso indevido destes espaços, inclusive já foi encontrado enterrado um objeto que oferecia perigo às crianças, sendo assim, segundo os educadores, não há mais como as crianças explorarem o espaço que está constantemente danificado. Esta concepção demonstra por um lado o reflexo do que predomina na maioria dos cursos de formação inicial e continuada de professores, com currículos fragmentados e descontextualizados que induzem à perpetuação da dificuldade de se visualizar as conexões e diálogo entre a realidade e o conhecimento, e por outro a emergência da superação deste cenário.

Nesse sentido outro ponto a ser destacado neste estudo foi a tomada de consciência dos professores durante as entrevistas realizadas sobre a insuficiência do seu conhecimento acerca da EA e em consequência de sua dificuldade quanto ao planejamento de atividades nesta área. Entre as falas que demonstraram esses aspectos foram selecionadas duas. Um dos professores do CMEl relatou ter realizado uma prática que considerava importante sobre preservação da água:

"Ano passado levamos as crianças num rio todo poluído e mostramos fotos do mesmo quando era limpo. Eles notaram a diferença. Mas hoje pensando, não sei o que eu poderia ter feito para aprofundar isso já que as crianças se interessaram tanto [...]".

Outro professor da rede privada revela que acredita ser importante o trabalho que desenvolve com o cuidado e preservação da água, mas percebe sua fragilidade no desenvolvimento do tema:

"Nós sempre trabalhamos aqui com a preservação da água, trabalhamos isso diariamente orientando as crianças a não desperdiçar água e tudo mais. Mas é isso EA? Não sei se é só isso [...] Acho que precisamos ter momentos para discutir e entender [...]".

Todas as falas dos professores da rede pública e da particular citaram os cuidados com o lixo e preservação da água como os temas trabalhados em EA, especialmente a separação do lixo e o cuidado com o desperdício da água quando na utilização de torneiras e chuveiro. Os relatos porém se limitaram a essas atividades pontuais e demonstraram a existência de um abismo entre os estudos acadêmicos acerca da EA e a prática dos professores da El. Este aspecto é um elemento preocupante visto que a EA somente conseguirá ser desenvolvida de forma crítica se os educadores refletirem e problematizarem suas práticas a partir do entendimento claro e consistente do objetivo da EA na El e de como as metodologias escolhidas influenciam na construção do pensamento, da identidade e da compreensão de mundo das crianças.

Durante a devolutiva dos resultados da pesquisa realizada às duas instituições, os professores e equipe pedagógica do CMEI sugeriram momentos de formação continuada sobe EA com as pesquisadoras. Essa formação será elaborada a partir dos resultados deste estudo e com as sugestões e participação dos educadores. Os educadores do CEI particular concordaram com o resultado, porém alegam que existem muitas dificuldades para a implantação da EA no seu cotidiano, como por exemplo, a utilização das apostilas que consomem grande parte do tempo com as crianças. Além disso ressaltaram que apesar de reconhecerem o caráter interdisciplinar na El o foco da instituição consiste na Linguagem Oral e Escrita e Matemática. Neste aspecto cabe uma preocupação quanto ao currículo na El, o qual segundo as DCNEI (2009) não se restringe às áreas mencionadas pelos educadores do CEI e sim tem como meta um trabalho pedagógico que apoie as crianças,

desde cedo e ao longo de suas experiências cotidianas no estabelecimento de uma relação positiva com a instituição educacional, no fortalecimento de sua autoestima, interesse e curiosidade pelo mundo, na familiaridade com as diferentes linguagens, e na aceitação e acolhimento das diferenças entre as pessoas". (OLIVEIRA, 2010, p. 9). 
A EDUCAÇÃO AMBIENTAL | Daniele Saheb e Daniela Gureski Rodrigues

Portanto constatou-se que as necessidades apontadas sobre a formação dos educadores de El em EA estendem-se à formação destes profissionais em todas as suas dimensões, inclusive no que diz respeito à compreensão do significado de uma El de qualidade adequada à proposta das DCNEI (2009). Este fato invoca processos de formação articulados à demanda de qualificar as práticas pedagógicas existentes e romper com modelos considerados inadequados de acordo com o que os documentos estudos orientam.

\section{5 | CONSIDERAÇÕES FINAIS}

Ao refletir sobre o processo de pesquisa realizado compreende-se que a $E A$, por meio de seus documentos orientadores e da prática pedagógica dos docentes, começa a delinear caminhos Educação Infantil. A EA implica em ressignificar a visão e compreensão de mundo a partir de uma concepção de integração, interconexão e inter-relacionamento. Afinal, os processos educacionais são essenciais para impulsionar a formação de uma cidadania ambiental. Assim, acredita-se que existe um longo caminho a seguir na formação inicial e continuada de professores que acolha os princípios da EA para que se contribua para a construção de um pensamento baseado no diálogo e nas inter-relações existentes entre a humanidade e o ambiente.

O estudo apontou que os PPP e os educadores das duas instituições apresentaram algum conhecimento sobre EA, bem como, consideraram a importância dessa temática na El. Porém, as informações apresentadas tanto pelos educadores quanto pelos PPP demonstraram ser insuficientes para os desdobramentos de boas práticas de EA na El. De acordo com os educadores de ambas as instituições inda é necessário que a EA seja mais trabalhada nos cursos de formação para que se possa ampliar e solidificar seu espaço nas discussões e práticas na Educação Infantil. 
A EDUCAÇÃO AMBIENTAL | Daniele Saheb e Daniela Gureski Rodrigues

\section{Referências}

BOFF, L. Sustentabilidade: o que é: o que não é. Petrópolis: Vozes, 2012.

BRASIL. Lei n 12.796 , de 4 de abril de 2013. Altera a Lei no 9.394 , de 20 de dezembro de 1996, que estabelece as diretrizes e bases da educação nacional, para dispor sobre a formação dos profissionais da educação e dar outras providências. Diário Oficial da União. Brasília, DF, 5 abr. 2013.

Lei $n^{\circ} 6.938$, de 31 de agosto de 1981. Dispõe sobre a Política Nacional do Meio Ambiente, seus fins e mecanismos de formulação e aplicação, e dá outras providências. Diário Oficial da União. Brasília, DF, 2 set. 1981.

. Lei $n^{\circ}$ 9.394, de 20 de dezembro de 1996. Estabelece as diretrizes e bases da educação nacional. Diário Oficial da União. Brasília, DF, 23 dez. 1996.

Ministério da Educação. Secretaria de Educação Básica. Diretrizes curriculares nacionais para a educação infantil. Brasília, DF: MEC; SEB, 2010.

Ministério da Educação e do Desporto. Secretaria de Educação Fundamental. Parâmetros curriculares nacionais: meio ambiente e saúde. Brasília, DF: MEC; SEF, 1997.

Ministério da Educação e do Desporto. Secretaria de Educação Fundamental. Referencial curricular nacional para a educação infantil. Brasília, DF: MEC; SEF, 1998. v. 1, 2 e 3.

Resolução CNE/CP $n^{\circ}$ 2, de 15 de junho de 2012. Estabelece as diretrizes curriculares nacionais para a educação ambiental. Diário Oficial da União, Brasília, DF, 18 jun. 2012. Seção 1, p. 70.

Resolução CNE/CEB n 5 , de 17 de dezembro de 2009 . Fixa as diretrizes curriculares nacionais para a educação infantil. Diário Oficial da União. Brasília, DF, 18 dez. 2009. Seção 1, p. 18.

Resolução CNE/CEB n ${ }^{\circ}$, de 7 de abril de 1999. Institui as diretrizes curriculares nacionais para a educação infantil. Diário Oficial da União, Brasília, DF, 13 abr. 1999. Seção 1, p. 18.
Resolução CNE/CP nº 01, de 15 de maio de 2006. Institui diretrizes curriculares nacionais para o curso de graduação em pedagogia, licenciatura. Diário Oficial da União, Brasília, DF, 16 maio 2006. Seção 1, p. 11.

CARVALHO, I. C. M. A invenção do sujeito ecológico: identidades e subjetividade na formação dos educadores ambientais. In: SATO, M.; CARVALHO, I. C. M. (Org.). Educação ambiental: pesquisa e desafios. Porto Alegre: Artmed, 2005.

Educação ambiental: a formação do sujeito ecológico. São Paulo: Cortez, 2004. (Coleção Docência em Formação).

CURITIBA. Prefeitura Municipal de Curitiba. Centro Municipal de Educação Infantil. Projeto político pedagógico. Curitiba: CMEI, 2004.

CURITIBA. Prefeitura Municipal de Curitiba. Centro Municipal de Educação Infantil. Projeto político pedagógico. Curitiba: CMEl, 2011.

CURITIBA. Prefeitura Municipal de Curitiba. Diretrizes curriculares para a educação municipal de Curitiba. Curitiba, 2012. Disponível em: http://www.cidadedoconhecimento.org.br/cidadedoconhecimento/downloads/arquivos/4319/download4319.pdf>. Acesso em: 05 jan. 2014.

GUARNIERI, M. R. (Org.). Aprendendo a ensinar: o caminho nada suave da docência. 2. ed. Campinas: Autores Associados, 2003.

OLIVEIRA, Z. de M. R. de. O currículo na educação infantil: o que propõe as novas diretrizes nacionais? In: SEMINÁRIO NACIONAL: O CURRÍCULO EM MOVIMENTO: PERSPECTIVAS ATUAIS, 1., 2010, Belo Horizonte. Anais... Belo Horizonte: [s.n.], 2010.

REIGOTA, M. Meio ambiente e representação social. São Paulo: Brasiliense, 1995.

TIRIBA, L. Crianças da natureza: educação ambiental para sociedades sustentáveis. Rio de Janeiro: PUC; NIMA, 2010. 